\title{
Predictors of BMI Vary along the BMI Range of German Adults - Results of the German National Nutrition Survey II
}

\author{
Kilson Moon ${ }^{a}$ Carolin Krems $^{a}$ Thorsten Heuer ${ }^{a} \quad$ Alexander Roth ${ }^{b}$ \\ Ingrid Hoffmann ${ }^{a}$ \\ a Department of Nutritional Behaviour, Max Rubner-Institut, Federal Research Institute of \\ Nutrition and Food, Karlsruhe, Germany; ${ }^{b}$ Department of Child and Adolescent Psychiatry \\ and Psychotherapy, University of Zurich, Zurich, Switzerland
}

\section{Key Words}

BMI · Adults · German National Nutrition Survey II · Predictors of BMI · Quantile regression

\section{Abstract}

Objective: The objective of the study was to identify predictors of BMI in German adults by considering the BMI distribution and to determine whether the association between BMI and its predictors varies along the BMI distribution. Methods: The sample included 9,214 adults aged 18-80 years from the German National Nutrition Survey II (NVS II). Quantile regression analyses were conducted to examine the association between BMI and the following predictors: age, sports activities, socio-economic status (SES), healthy eating index-NVS II (HEI-NVS II), dietary knowledge, sleeping duration and energy intake as well as status of smoking, partner relationship and self-reported health. Results: Age, SES, self-reported health status, sports activities and energy intake were the strongest predictors of BMI. The important outcome of this study is that the association between BMI and its predictors varies along the BMI distribution. Especially, energy intake, health status and SES were marginally associated with BMI in normal-weight subjects; this relationships became stronger in the range of overweight, and were strongest in the range of obesity. Conclusions: Predictors of BMI and the strength of these associations vary across the BMI distribution in German adults. Consequently, to identify predictors of BMI, the entire BMI distribution should be considered. 
Moon et al.: Predictors of BMI Vary along the BMI Range of German Adults - Results of the German National Nutrition Survey II

\section{Introduction}

One of the major public health problems world-wide and also in Germany is the high prevalence of overweight and obesity [1]. Recent data from the World Health Organization show that since 1980 the prevalence of obesity has nearly doubled world-wide [2], and in 2014 for adults aged 18 years and older the prevalence of overweight and obesity was 39\% and $13 \%$, respectively. In Germany, the prevalence of overweight was $44 \%$ for adult men and $29 \%$ for adult women, while the prevalence of obesity was $23 \%$ for men and $24 \%$ for women [3].

The aetiology of overweight and obesity is complex and multifactorial [4]. Factors associated with BMI are age, sex, socio-economic status (SES), nutritional behaviour, physical activity, smoking and sleeping behaviour [5-10]. Results of numerous studies investigating the association between BMI and its predictors are partly inconsistent, e.g., regarding the association between energy intake and BMI. Some studies show high energy intakes in subjects with high BMI $[11,12]$, some authors did not find such an association $[13,14]$, and few studies observed lower energy intake with higher BMI $[15,16]$. Reasons for contradicting results could be different study designs, study populations or methods of measurement. Another reason could be underreporting. Different percentages of underreporters in previous studies may bias the results concerning the association between BMI and energy intake. Furthermore, most of the studies are based on the assessment of mean BMI, and analyses are mainly carried out without differentiation across the entire BMI distribution.

The aim of the present study was to identify predictors of the BMI by including a large set of potential predictor variables and to determine whether the association between BMI and its predictors varies along the range of BMI in the German adult population using data of the German National Nutrition Survey II (NVS II). For this, a quantile regression model was applied which allows identifying predictors of BMI along the BMI distribution. In contrast to conventional statistical methods, such as multiple linear or logistic regressions, which are inconsistent in the presence of heteroscedasticity $[17,18]$, the quantile regression is robust against outliers, and no subjects need to be excluded. Therefore, this statistical method is suitable for population studies with a broad range of BMI.

\section{Material and Methods}

Data of NVS II, a representative cross-sectional study of the German population conducted in 20052007, were used. The aim of the study was to evaluate food consumption and other aspects of nutritional behaviour of a representative sample of the German population. The participants were 14-80 years of age, German speaking and living in private households. A detailed description of the NVS II study design was published previously [19]. Methods (instruments, measurements and statistics) relating to the analysis of the association between BMI and predictors of BMI are described below.

\section{Anthropometric Measurements}

Body height (in $\mathrm{cm}$, with a precision of $0.1 \mathrm{~cm}$ ) and weight (in $\mathrm{kg}$, with a precision of $0.1 \mathrm{~kg}$ ) were measured according to Lohmann et al. [20] with a portable Harpenden Stadiometer (Holtain Ltd., Crymych, UK) and the calibrated scale seca 862 (Seca Vogel \& Halke, Hamburg, Germany) after shoes, coats and sweaters had been taken off. In addition, an amount of $1 \mathrm{~kg}$ was subtracted from the body weight to exclude the weight of light clothing. BMI was calculated using the formula body weight (in $\mathrm{kg}$ ) / body height (in $\mathrm{m})^{2}$. According to the World Health Organization Growth Reference, normal-weight participants have a BMI between 18.5 and $24.9 \mathrm{~kg} / \mathrm{m}^{2}$, overweight participants have a BMI between 25.0 and $29.9 \mathrm{~kg} / \mathrm{m}^{2}$, and obese participants have a BMI of $30.0 \mathrm{~kg} / \mathrm{m}^{2}$ or higher [2]. 
Moon et al.: Predictors of BMI Vary along the BMI Range of German Adults - Results of the German National Nutrition Survey II

\section{Dietary Assessment}

The usual food consumption of the past 4 weeks (15,371 individuals) was assessed face-to-face by a computer-assisted diet history interview in a study centre using the dietary assessment programme DISHES (Diet Interview Software for Health Examination Studies). Tableware models (cups, glasses, spoons, plates and bowls) and a picture book with different portion sizes of food items were used for quantification of consumed amounts $[19,21]$. In order to calculate energy intake the food consumption data were matched with the energy contents of the German Nutrient Database (BLS 3.02) [22]. The healthy eating index-NVS II (HEI-NVS II) was developed in the frame of the NVS II to measure how well diets meet food-based dietary guidelines of the German Nutrition Society [23, 24]. The HEI-NVS II is composed of 10 food components (grains, vegetables, fruit, milk, meat, fish, eggs, spreadable fats, non-alcoholic beverages and alcohol), each with a maximum score of 10 points, except for the components fruit and vegetables with a maximum of 15 points each (total range 0 to 110).

\section{Predictors of BMI and Study Group}

A computer-assisted personal interview and, complementary, a self-administered questionnaire were applied to obtain socio-demographic data as well as information on time spent with sports activities, dietary knowledge, sleeping behaviour, smoking status, partner relationship status and self-reported health status. Only sports activities like hiking, swimming or playing tennis were assessed which represent a part of daily physical activities.

An index of SES was created based on the 'Winkler-Index' [25], using school education of the participant and employment status of the principal earner of the household, which were each coded as $1=$ lowest and $8=$ highest. Additionally, net monthly income of the household, which was coded as $1=$ lowest and $9=$ highest (total range 3-25), completed the SES index. The dietary knowledge index was developed using a point system with questionnaire items about general knowledge on food and healthy nutrition (maximum 18 points). The average daily sleeping duration was calculated with the average number of hours participants slept on weekdays and weekends. Smoking status was categorized as $0=$ current smoker and $1=$ non-smoker (including ex-smokers). The partner relationship status was classified as $0=$ living with a partner (married or cohabiting) and 1 = living alone (single, widowed or divorced). The self-reported heath status of the subjects was categorized as $0=$ good and $1=$ fair or poor health.

For the present analyses, only subjects with complete data sets on measured body weight and height and all selected predictors of BMI were included $(n=13,079$ from 15,371). In addition, adolescents 14-17 years of age, pregnant and nursing women $(n=1,328)$ as well as underreporters based on the method by Goldberg et al. [26] and Black [27] $(n=2,537)$ were excluded. This resulted in a final study population of 9,214 subjects $18-80$ years of age. The analyses were carried out by sex, because men and women might have different predictors of BMI.

\section{Statistical Analyses}

Quantile regression [18] was applied to assess the predictors of BMI. In the models, the conditional quantile functions at different quantiles were estimated from the 5 th to 95 th quantile with $5 \%$ distance. In the regression model, the dependent variable was BMI and the independent variables were age, sports, SES index, HEI-NVS II, dietary knowledge index, sleeping duration, energy intake, smoking status, partner relationship status and self-reported health status. The variable squared age was additionally included because a quadratic effect of age on BMI is shown in a wide age range of the study population. The estimated variance inflation factors for the independent variables ranged from 1.01 to 1.62, suggesting that multicollinearity was not a problem in these analyses. The mean values of the mentioned variables in women and men were tested using standard error of the means at 5\% probability level. The quantile regression was carried out using PROC QUANTREG in SAS Version 9.3 (SAS Institute, Cary, NC, USA) and considered significant at $\mathrm{p}<0.05$. A Markov chain marginal bootstrap was used to calculate confidence intervals for quantiles.

\section{Results}

A total of 9,214 participants were included in the present study $(4,268$ men and 4,946 women). The average BMI of the study population was $26.5 \mathrm{~kg} / \mathrm{m}^{2}$ in men and $25.2 \mathrm{~kg} / \mathrm{m}^{2}$ in women (table 1). The prevalence of overweight was about $47 \%$ in men and $29 \%$ in women, 
Moon et al.: Predictors of BMI Vary along the BMI Range of German Adults - Results of the German National Nutrition Survey II

Table 1. Distribution of BMI and BMI predictors by sex

\begin{tabular}{|c|c|c|c|c|c|c|c|c|}
\hline & \multicolumn{4}{|c|}{ Men $(n=4,268)$} & \multicolumn{4}{|c|}{ Women $(n=4,946)$} \\
\hline & mean & SE & median & 5-95 percentiles & mean & SE & median & 5-95 percentiles \\
\hline BMI, $\mathrm{kg} / \mathrm{m}^{2}$ & 26.5 & 0.06 & 26.2 & $20.6-33.3$ & 25.2 & 0.07 & 24.3 & $19.2-34.1$ \\
\hline Age, years & 49 & 0.3 & 49 & $20-74$ & 48 & 0.2 & 48 & $21-73$ \\
\hline SES index (range $3-25)^{\dagger}$ & 16 & 0.1 & 16 & $9-23$ & 15 & 0.1 & 16 & $8-22$ \\
\hline Energy intake, kcal/day ${ }^{\dagger}$ & 2,837 & 11.8 & 2,675 & $1,975-4,242$ & 2,148 & 7.3 & 2,063 & $1,512-3,074$ \\
\hline Sports, h/week ${ }^{\dagger}$ & 5.6 & 0.12 & 3 & $0-20$ & 3.8 & 0.08 & 2 & $0-14$ \\
\hline HEI-NVS II (range $0-110)^{\ddagger}$ & 79 & 0.2 & 80 & $61-96$ & 85 & 0.1 & 86 & $69-99$ \\
\hline Sleep duration, h/day ${ }^{\ddagger}$ & 7.2 & 0.02 & 7.1 & $5.5-8.6$ & 7.3 & 0.01 & 7.3 & $5.5-8.7$ \\
\hline $\begin{array}{l}\text { Dietary knowledge index } \\
\quad \text { (range } 0-18)^{\ddagger}\end{array}$ & 11 & 0.1 & 11 & $5-17$ & 13 & 0.1 & 14 & $7-18$ \\
\hline $\begin{array}{l}\text { Good health / fair or poor } \\
\text { health, } \%\end{array}$ & 77.2 / 22.8 & & & & 78.7 / 21.3 & & & \\
\hline Smoker / non-smoker, \% & $28.1 / 71.9$ & & & & $21.1 / 78.9$ & & & \\
\hline $\begin{array}{l}\text { Living with partner / living } \\
\text { alone, \% }\end{array}$ & 74.6 / 25.4 & & & & $71.1 / 28.9$ & & & \\
\hline
\end{tabular}

SES = Socio-economic status; HEI-NVS II = healthy eating index-NVS II.

${ }^{\dagger}$ The mean value is significantly higher in men than in women $(\mathrm{p}<0.05)$.

${ }^{\ddagger}$ The mean value is significantly higher in women than in men $(\mathrm{p}<0.05)$.

and the prevalence of obesity was $17 \%$ in men and $15 \%$ in women. The mean values of sports activities, SES index and energy intake were higher in men than in women, whereas mean values of HEI-NVS II, dietary knowledge index and sleep duration were higher in women.

Results of selected quantile regression estimates at the 5th, 25th, 50th, 75th and 95th quantiles for all variables including t-value are presented in table 2 for men and in table 3 for women. Full details of the quantile regression including 95\% confidence intervals based on bootstrap standard errors are provided in figures 1 and 2 .

Across the entire BMI range of men, age was positively associated with BMI (table 2). The association of BMI and age across all age groups was not linear but rather quadratic, which indicates that the BMI becomes higher until middle age and remains relatively stable in older subjects. There was also a positive association between age and BMI for women (table 3). A negative quadratic effect of age on BMI was shown in women with overweight and obesity, but not in normal-weight women.

A negative association between duration of weekly sports activities and BMI exists: a high BMI was associated with less time spent with sports activities in men (BMI quantile 35th90th; fig. 1) and for women (BMI quantile 5th-90th; fig. 2). At the 95th BMI quantile, no association of BMI with sports was observed in either sex.

The SES index was negatively associated with BMI for both sexes across the entire BMI distribution. This association became stronger towards the upper tail of the BMI range. In the range of normal weight, SES was stronger associated with BMI than other predictors. Moreover, among women who are at the lowest part of normal weight, SES is the strongest predictor.

There was no association between HEI-NVS II and BMI in men (except for the 5th quantile), whereas a positive association was shown in women.

Results of quantile regression showed no association between the dietary knowledge index and BMI for both sexes. 
Moon et al.: Predictors of BMI Vary along the BMI Range of German Adults - Results of the German National Nutrition Survey II

Table 2. Association between BMI and predictors at selected quantiles of the quantile regression $($ men, $n=4,268)$

\begin{tabular}{|c|c|c|c|c|c|c|c|c|c|c|}
\hline & \multicolumn{2}{|c|}{$\begin{array}{l}0.05 \text { Quantile } \\
\left(\text { BMI } 20.6 \mathrm{~kg} / \mathrm{m}^{2}\right)\end{array}$} & \multicolumn{2}{|c|}{$\begin{array}{l}0.25 \text { Quantile } \\
\left(\text { BMI } 23.8 \mathrm{~kg} / \mathrm{m}^{2}\right)\end{array}$} & \multicolumn{2}{|c|}{$\begin{array}{l}0.50 \text { Quantile } \\
\left(\text { BMI } 26.2 \mathrm{~kg} / \mathrm{m}^{2} \text { ) }\right.\end{array}$} & \multicolumn{2}{|c|}{$\begin{array}{l}0.75 \text { Quantile } \\
\left(\text { BMI } 28.9 \mathrm{~kg} / \mathrm{m}^{2}\right)\end{array}$} & \multicolumn{2}{|c|}{$\begin{array}{l}0.95 \text { Quantile } \\
\left(\text { BMI } 33.3 \mathrm{~kg} / \mathrm{m}^{2}\right)\end{array}$} \\
\hline & estimate & t-value & estimate & t-value & estimate & t-value & estimate & t-value & estimate & t-value \\
\hline Intercept & $17.84^{* * *}$ & 17.81 & $22.89^{* * *}$ & 25.56 & $25.50^{* * *}$ & 22.16 & $28.54^{* * *}$ & 25.60 & $33.21^{* * *}$ & 15.52 \\
\hline Age, years & $0.05^{* * *}$ & 10.89 & $0.06^{* * *}$ & 12.33 & $0.06^{* * *}$ & 13.45 & $0.06^{* * *}$ & 9.45 & $0.07^{* * *}$ & 4.97 \\
\hline Age $\times$ age & $-0.27^{* * *}$ & -3.67 & $-0.32^{* * *}$ & -4.40 & $-0.43^{* * *}$ & -6.49 & $-0.55^{* * *}$ & -6.23 & $-0.50^{*}$ & -2.36 \\
\hline SES index & $-0.04^{*}$ & -2.48 & $-0.07^{* * *}$ & -4.20 & $-0.09^{* * *}$ & -5.68 & $-0.09^{* * *}$ & -4.80 & $-0.14^{* * *}$ & -3.81 \\
\hline Good health $^{\dagger}$ & 0.19 & 0.93 & $-0.71^{* * *}$ & -3.72 & $-0.97^{* * *}$ & -5.95 & $-1.22^{* * *}$ & -4.97 & $-1.77^{* * *}$ & -4.14 \\
\hline Energy intake, kcal/day & -0.0000 & -0.28 & 0.0001 & 0.72 & 0.0001 & 1.75 & $0.0004^{* *}$ & 3.07 & $0.0014^{* * *}$ & * 4.53 \\
\hline Sports, h/week & 0.001 & 0.04 & -0.004 & -0.51 & $-0.02^{* *}$ & -3.06 & $-0.05^{* * *}$ & -5.89 & -0.03 & -1.47 \\
\hline Smoker ${ }^{\dagger}$ & $-0.74^{* * *}$ & -3.83 & $-0.67^{* * *}$ & -4.20 & $-0.55^{* * *}$ & -3.72 & $-0.62^{* *}$ & -2.91 & $-1.19^{* * *}$ & -3.41 \\
\hline Living with partner ${ }^{\dagger}$ & $0.70^{* * *}$ & 3.36 & $0.70^{* * *}$ & 3.58 & $0.90^{* * *}$ & 5.28 & $0.54^{*}$ & 2.03 & 0.26 & 0.57 \\
\hline HEI-NVS II & $0.02^{* *}$ & 2.65 & 0.003 & 0.50 & 0.005 & 0.72 & 0.006 & 0.65 & -0.03 & -1.66 \\
\hline Dietary knowledge index & -0.01 & -0.43 & -0.03 & -1.33 & -0.02 & -1.08 & -0.02 & -0.68 & 0.01 & 0.28 \\
\hline Sleep duration, h/day & -0.01 & -0.18 & -0.05 & -0.67 & -0.11 & -1.72 & -0.16 & -1.82 & -0.17 & -0.97 \\
\hline
\end{tabular}

SES = Socio-economic status; HEI-NVS II = healthy eating index-NVS II.

${ }^{\dagger}$ Reference categories are as follows: smoker vs. non-smoker, living with partner vs. living alone, good health vs. poor or fair health.

$$
{ }^{*} \mathrm{p}<0.05,{ }^{* *} \mathrm{p}<0.01,{ }^{* * *} \mathrm{p}<0.001 .
$$

Table 3. Association between BMI and predictors at selected quantiles of the quantile regression (women, $n=4,946)$

\begin{tabular}{|c|c|c|c|c|c|c|c|c|c|c|}
\hline & \multicolumn{2}{|c|}{$\begin{array}{l}0.05 \text { Quantile } \\
\left(\text { BMI } 19.2 \mathrm{~kg} / \mathrm{m}^{2} \text { ) }\right.\end{array}$} & \multicolumn{2}{|c|}{$\begin{array}{l}0.25 \text { Quantile } \\
\left(\text { BMI } 21.8 \mathrm{~kg} / \mathrm{m}^{2}\right)\end{array}$} & \multicolumn{2}{|c|}{$\begin{array}{l}0.50 \text { Quantile } \\
\left(\text { BMI } 24.3 \mathrm{~kg} / \mathrm{m}^{2}\right)\end{array}$} & \multicolumn{2}{|c|}{$\begin{array}{l}0.75 \text { Quantile } \\
\left(\text { BMI } 27.7 \mathrm{~kg} / \mathrm{m}^{2}\right)\end{array}$} & \multicolumn{2}{|c|}{$\begin{array}{l}0.95 \text { Quantile } \\
\left(\mathrm{BMI} 34.1 \mathrm{~kg} / \mathrm{m}^{2}\right)\end{array}$} \\
\hline & estimate & t-value & estimate & t-value & estimate & t-value & estimate & t-value & estimate & t-value \\
\hline Intercept & $16.99^{* * *}$ & 21.79 & $19.99^{* * *}$ & 24.83 & $22.91^{* * *}$ & 23.18 & $24.45^{* * *}$ & 20.22 & $24.90^{* * *}$ & 10.25 \\
\hline Age, years & $0.05^{* * *}$ & 11.86 & $0.07^{* * *}$ & 16.38 & $0.08^{* * *}$ & 15.80 & $0.09^{* * *}$ & 13.95 & $0.07^{* * *}$ & 5.74 \\
\hline Age $\times$ age & 0.10 & 1.49 & -0.10 & -1.63 & -0.07 & -0.96 & -0.18 & -1.91 & $-0.61_{* * *}^{* *}$ & -3.12 \\
\hline SES index & $-0.06^{* * *}$ & -4.24 & $-0.11^{* * *}$ & -7.92 & $-0.16^{* * *}$ & -9.37 & $-0.22^{* * *}$ & -9.79 & $-0.29^{* * *}$ & -6.59 \\
\hline Good health $^{\dagger}$ & -0.17 & -0.66 & $-0.83^{* * *}$ & -4.63 & $-1.28^{* * *}$ & -6.31 & $-1.98^{* * *}$ & -8.53 & $-3.65^{* * *}$ & -7.54 \\
\hline Energy intake, kcal/day & -0.0001 & -0.53 & 0.0001 & 1.09 & $0.0005^{* *}$ & 3.08 & $0.0016^{* * *}$ & *7.59 & $0.0042^{* * *}$ & 9.71 \\
\hline Sports, h/week & $-0.02^{* *}$ & -3.07 & $-0.03^{*}$ & -2.37 & $-0.04^{* * *}$ & -4.81 & $-0.07^{* * *}$ & -5.58 & -0.06 & -1.44 \\
\hline Smoker ${ }^{+}$ & $-0.40^{*}$ & -2.21 & $-0.39^{* *}$ & -3.07 & $-0.55^{* * *}$ & -3.44 & $-0.84^{* * *}$ & -4.05 & -0.53 & -1.23 \\
\hline Living with partner ${ }^{\dagger}$ & $0.43^{* *}$ & 2.84 & $0.42^{* *}$ & 3.22 & $0.36^{*}$ & 2.18 & $0.41^{*}$ & 1.97 & 0.36 & 0.72 \\
\hline HEI-NVS II & $0.02^{* *}$ & 3.12 & $0.02^{* *}$ & 3.27 & $0.02^{* *}$ & 2.61 & $0.02^{*}$ & 2.35 & 0.04 & 1.86 \\
\hline Dietary knowledge index & -0.01 & -0.62 & -0.03 & -1.76 & -0.01 & -0.67 & -0.01 & -0.46 & 0.01 & 0.25 \\
\hline Sleep duration, h/day & -0.04 & -0.85 & -0.04 & -0.64 & $-0.16^{*}$ & -2.27 & $-0.19^{*}$ & -2.10 & 0.02 & 0.11 \\
\hline
\end{tabular}

SES = Socio-economic status; HEI-NVS II = healthy eating index-NVS II.

${ }^{\dagger}$ Reference categories are as follows: smoker vs. non-smoker, living with partner vs. living alone, good health vs. poor or fair health.

${ }^{*} \mathrm{p}<0.05,{ }^{* *} \mathrm{p}<0.01,{ }^{* *} \mathrm{p}<0.001$.

For sleep duration and BMI, there was a statistically significant weak negative association for men, particularly at the middle and high BMI quantiles. In women, a slight negative association was observed across the 45th-85th quantiles of the BMI range.

For both sexes, the association between energy intake and BMI varied across the BMI distribution. In men, a positive association between energy intake and BMI was observed at 
Moon et al.: Predictors of BMI Vary along the BMI Range of German Adults - Results of the German National Nutrition Survey II

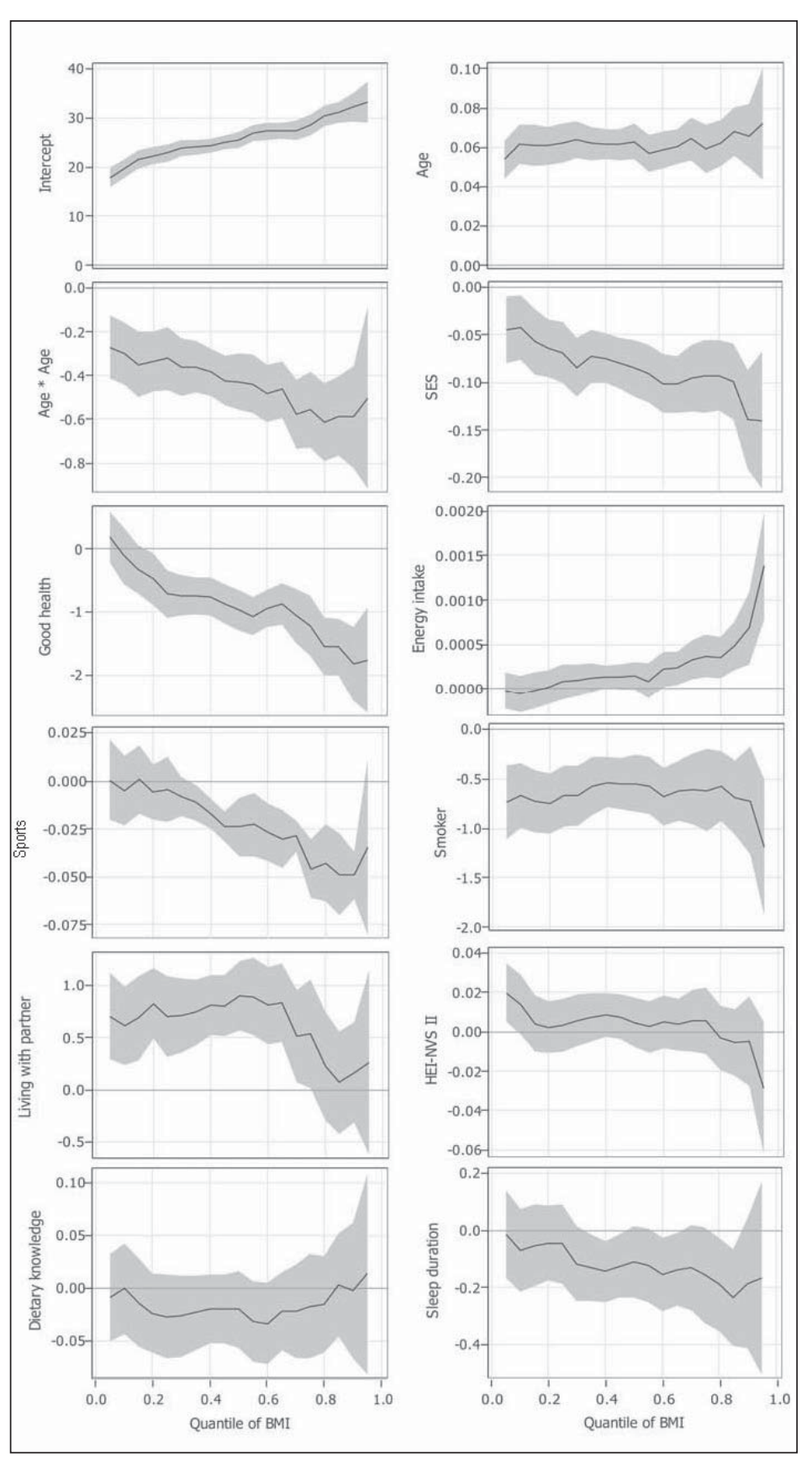

Fig. 1. Quantile regression estimation for predictors of BMI in men. The solid line indicates the quantile regression estimates and the shaded area the $95 \%$ confidence interval.

higher BMI quantiles beyond the 60th quantile (BMI $27.2 \mathrm{~kg} / \mathrm{m}^{2}$ ), but not at the lower and middle quantiles. This means that the BMI is only associated with energy intake in men with overweight and obesity. In women, the positive association was statistically significant in the 45th quantile (BMI $23.8 \mathrm{~kg} / \mathrm{m}^{2}$ ) and was stronger associated towards the upper tail of the BMI range.

A negative association was observed between smoking and BMI. Smokers had a lower BMI than non-smokers, except at the uppermost tail of the BMI range in women where no association with regard to smoking was detected. 
Moon et al.: Predictors of BMI Vary along the BMI Range of German Adults - Results of the German National Nutrition Survey II

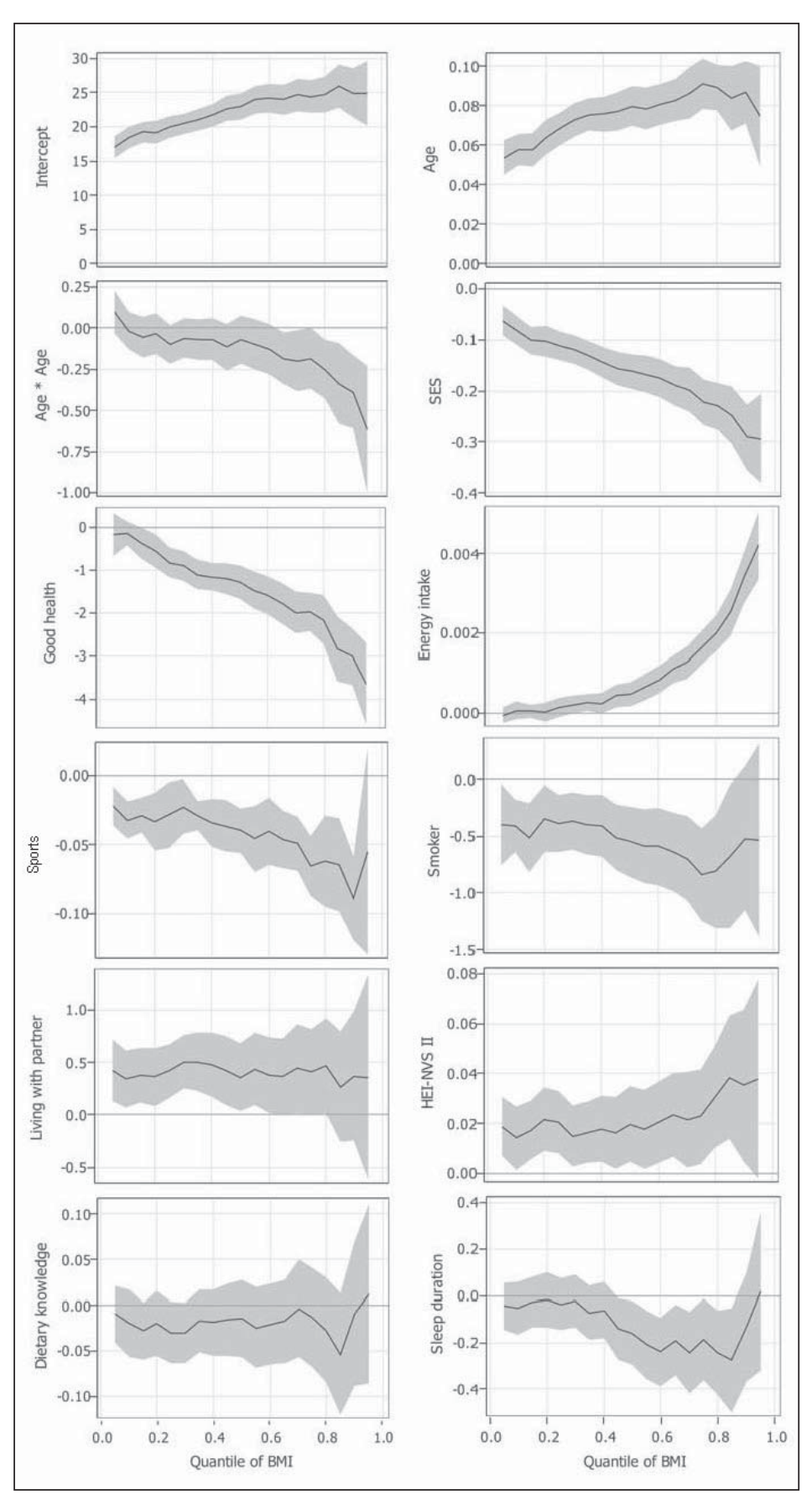

Fig. 2. Quantile regression estimation for predictors of BMI in women. The solid line indicates the quantile regression estimates and the shaded area the $95 \%$ confidence interval.

At the lower and middle BMI quantiles, women and men living with a partner showed a higher BMI than people living alone. At higher BMI quantiles, representing obesity, no differences between the two groups were observed.

Beyond the 20th BMI quantile in men (BMI $23.2 \mathrm{~kg} / \mathrm{m}^{2}$ ) and women (BMI $21.3 \mathrm{~kg} / \mathrm{m}^{2}$ ), there was an association between self-reported health status and BMI. The participants who described themselves as being in good health had a lower BMI than those describing themselves as being in fair or poor health. Differences in BMI regarding the two categories of selfreported health status increased continuously up to highest BMI quantiles and were largest 
Moon et al.: Predictors of BMI Vary along the BMI Range of German Adults - Results of the German National Nutrition Survey II

at the uppermost BMI range where men and women with good health status showed a reduced BMI $\left(-1.77 \mathrm{~kg} / \mathrm{m}^{2}\right.$ and $-3.65 \mathrm{~kg} / \mathrm{m}^{2}$, respectively). At lower BMI quantiles, there was no association between health status and BMI.

\section{Discussion}

The present cross-sectional study identified predictors of BMI in the German adult population considering the distribution of BMI. Results indicate that the BMI is strongly associated with energy intake (in the range of overweight and obesity), age, SES, self-reported health status, and sports activities. An important outcome of the present study is that the strength of the association between BMI and these factors varies substantially across the BMI distribution. These associations are generally stronger towards the higher BMI ranges. Sex differences were only observed at lower and middle BMI ranges.

Many studies including a systematic review suggested that the BMI is positively associated with energy intake $[11,12]$; however, other studies found no $[13,14]$ or negative $[15$, 16] associations. These latter findings might partially be caused by underreporting in selfreported dietary intake. It is known that individuals with overweight and obesity tend to underreport their food consumption which leads to an underestimation of total energy intake [28]. In the NVS II participants, the proportion of underreporters was also higher in subjects with overweight and obesity than in normal-weight subjects.

The proportionally higher rate of underreporting in subjects with overweight and obesity than in those with normal weight would bias the association of energy intake and BMI. Independent of outcome, in studies investigating the impact of food consumption or nutrient intake on BMI, frequently the number of underreporters in the study population was not determined [11-15]. Furthermore, in other studies, the associations between energy intake and BMI are usually analysed by conventional statistical approaches, which are based on mean value analysis. These statistics suffer from a lack of sensitivity for outliers, values distant from the mean, which could have a strong influence on the results. Accordingly, the present study investigated the statistical model of quantile regression which is robust against outliers and considers the entire BMI distribution. The results furthermore suggested that the association of BMI and energy intake differs not only between BMI categories (normal weight, overweight and obesity), but also within in each BMI category which consists of several quantiles. To our knowledge there is only one other study [7] in which the predictors of BMI were examined along the BMI distribution in a population-based survey using the quantile regression method. The study by Shankar [7] with 3,407 Chinese adults 20-45 years of age also showed a positive association between energy intake and BMI for most quantiles in the overweight and obesity range, but not for all quantiles in the normal-weight range.

In most previous studies BMI was calculated from self-reported height and weight. Studies comparing self-reported and measured BMI showed that subjects with overweight and obesity tend to underestimate BMI values $[29,30]$. This may lead to an incorrect classification of subjects with overweight and obesity and may thereby influence the results regarding the association between BMI and energy intake.

The exclusion of underreporters as well as the use of the statistical model of quantile regression and of measured BMI data in the present study delivered more detailed information regarding the association between BMI and energy intake than previous studies based on the use of mean values and the data of self-reported BMI without exclusion of underreporters. The design of the present cross-sectional study does not allow interpreting the results as causal associations; it is not clear whether a higher energy intake leads to a higher 
Moon et al.: Predictors of BMI Vary along the BMI Range of German Adults - Results of the German National Nutrition Survey II

BMI or, conversely, whether a higher BMI generally means more mass and hence higher energy intake to maintain body weight.

Despite differences in study design and statistical methods of numerous studies and the present study, the results regarding the association of BMI and various predicting factors (age, SES, health status, sports activities and smoking) headed in the same direction. Additionally, the findings of the present study provided more detailed information regarding these associations for each BMI quantile.

In agreement with previous studies [7,31,32], the present study demonstrated a positive linear association of BMI with age. The quadratic effect of age on the BMI had also been consistently observed in other studies [5,33]. Moreover, the present investigation showed that age is the strongest predictors of BMI in all BMI ranges in both sexes.

SES was found to be a significant predictor of obesity [10,34]. Studies in the literature reported that individuals with a high SES which means a high education $[35,36]$, high-level of employment [37, 38] and high household income [37,39], are likeky to have more opportunities for healthy eating and physical activity which resulted in a lower prevalence of obesity. Previous analyses of NVS II data showed that participants with a higher SES consumed more food with a lower energy density like vegetables and fruit, while participants with a lower SES ate more food with a higher energy density like meat and meat products [19]. The negative association between BMI and SES was reported in several previous studies [10, 34-39]. Also in the present study, the negative association was observed across the entire BMI distribution of the study population but differentiated results are provided. The association turned progressively stronger towards overweight and obesity.

Previous investigations reported that subjects with obesity were more likely to have a poor self-reported health status $[40,41]$. Likewise, in the present study a negative association between self-reported health status and BMI was observed in subjects with overweight and obesity, but not in all normal-weight subjects.

Higher levels of physical activity are associated with lower BMI [8, 42]. For participants of the present study, this negative association between duration of weekly sports activities and BMI was also shown. By differentiating the BMI distribution, sports activities are one of the strongest predictors of BMI in the range of overweight and obesity (except at the highest BMI range), whereas no or a weak association was found in the range of normal weight. Sports activities are only one aspect of total physical activity. Other aspects, such as household chores or occupational activities, which also contribute to total physical activity, were not assessed in the present study. Therefore, these results should be interpreted with caution.

The negative association between smoking and BMI in the present study is consistent with some studies $[9,43]$. This association is shown across the entire BMI distribution, except for obese women. Similar results were observed in the study of Shankar [7] who found a negative association of smoking with BMI in the range of normal weight and overweight, but not in all ranges of obesity.

Previous studies found a higher BMI in individuals living with a partner than in those living alone and suggested that this may be due to the influence of marriage and divorce on change in health behaviours, for example, inducements to eat or motivation for weight control $[44,45]$. The results of the present study which considered the differentiation of BMI distribution showed that the status of partner relationship was associated with BMI only among persons with normal weight and overweight.

A positive association between HEI-NVS II, a measure of the overall quality of diet, and BMI was observed in women, but not in men. This means that women eating foods in amounts according to the dietary guidelines of the German Nutrition Society have a higher BMI. At first glance this finding is in contrast to studies that found a negative association between US-HEI and BMI $[46,47]$. At second glance, however, this may be explained by the diverging back- 
Moon et al.: Predictors of BMI Vary along the BMI Range of German Adults - Results of the German National Nutrition Survey II

ground of the indexes: While the HEI-NVS II is based on the absolute amounts recommended in the German dietary guidelines which do not consider energy intake, the US-HEI applied in the cited literature is based on food consumption and nutrient intake in relation to energy intake. For the HEI-NVS II this means that the consumption of large amounts independent of energy intake (and therefore overeating) may lead to high scores. Since the US-HEI takes into account energy intake, persons with favourable consumption and adequate energy intake more easily reach high scores.

The strength of the present study is the use of representative population data from the NVS II. Because of the large sample size, it was possible to exclude underreporters and to stratify for sex and to provide thereby the statistical power to determine the associations with BMI. In contrast to previous studies, only subjects with measured body height and weight data were included in the present study.

A limitation of the present study is the cross-sectional design of the NVS II, which does not allow analysis of causes and effects regarding the association between BMI and the predictors. In this regard, longitudinal studies will be useful to explore the cause-effect associations, especially for the aspects of BMI and energy intake or health status. Moreover, the data of NVS II, which was collected from 2005 to 2007, provides information regarding the predictors of BMI at that point in time. These results therefore need to be interpreted with caution. Another limitation is that all variables, except of body height and weight, are selfreported, which could lead to errors in reporting. Also, the assessment of weekly sports activities by a self-reported questionnaire provides no information regarding total energy expenditure. Therefore, energy balance could not be considered in the present study. Food consumption was assessed using a diet history interview. This method is more suitable to estimate usual energy intake for the investigation of long-term effects on body weight than short-term methods (e.g. 24-hour recall). However, it requires high cognitive skills of the study participants to remember the consumption of the past 4 weeks, which could lead to inaccurate estimations of energy intake and therefore influence the associations with BMI [48].

In summary, in the German adult population predictors of BMI and the strength of the associations varied across the BMI distribution. The associations were generally stronger in the range of overweight and obesity than in the range of normal weight. In the overweight and obese subjects, energy intake, age, health status and SES were the most relevant predictors of BMI. Energy intake and age showed a positive association with BMI, whereas health status and SES were negatively associated with BMI. In all BMI ranges, strong associations of age and BMI were observed. The other three predictors were marginal in normal-weight subjects, became stronger in overweight and were strongest in obese subjects. Furthermore, the strength regarding the associations between BMI and the predictors differed between men and women with normal weight and overweight, but no differences were found between obese men and women. These findings support target group-specific nutrition counselling and policy guidance. Additionally, the results underline that the differentiation between BMI ranges is a prerequisite for future research on overweight and obesity.

\section{Acknowledgments}

The authors thank Prof. Bernhard Watzl (Max Rubner-Institut, Department of Physiology and Biochemistry of Nutrition, Karlsruhe) for helpful comments and critical review of the paper.

The NVS II was funded by the German Federal Ministry of Food and Agriculture. The Ministry had no role in the design, analysis or writing of this article.

The authors' contributions are as follows: K.M was responsible for analysing and interpreting the data and writing the article; C.K. and T.H. were involved in study design, data interpretation, manuscript prepa- 
Moon et al.: Predictors of BMI Vary along the BMI Range of German Adults - Results of the German National Nutrition Survey II

ration and critically reviewed the manuscript; A.R. contributed to statistical analyses and data interpretation; I.H. contributed to data interpretation, critically reviewed the manuscript and had primary responsibility for the final content. All authors read and approved the final version of the manuscript.

\section{Disclosure Statement}

None of the authors declared any conflict of interest.

\section{References}

1 World Health Organization: Obesity: Preventing and Managing the Global Epidemic. Report of a WHO consultation. WHO Technical Report. Geneva, World Health Organization, 2009.

2 World Health Organization: Obesity and Overweight. Factsheet. Updated June 2016. 2014. www.who.int/mediacentre/factsheets/fs311/en/ (last accessed January 30, 2017).

-3 Mensink GB, Schienkiewitz A, Haftenberger M, Lampert T, Ziese T, Scheidt-Nave C: Overweight and obesity in Germany: results of the German Health Interview and Examination Survey for Adults (DEGS1) (in German). Bundesgesundheitsbl Gesundheitsforsch Gesundheitsschutz 2013;56:786-794.

4 Schneider K, Hoffmann I: Potentials of qualitative modelling of complex health issues. Am J Health Behav 2011; 35:557-567.

5 Arabshahi S, Lahmann PH, Williams GM, van der Pols JC: Predictors of change in weight and waist circumference: 15-year longitudinal study in Australian adults. Eur J Clin Nutr 2014;68:309-315.

-6 Grandner MA, Chakravorty S, Perlis ML, Oliver L, Gurubhagavatula I: Habitual sleep duration associated with self-reported and objectively determined cardiometabolic risk factors. Sleep Med 2014;15:42-50.

7 Shankar B: Obesity in China: the differential impacts of covariates along the BMI distribution. Obesity (Silver Spring) 2010;18:1660-1666.

8 Dunton GF, Berrigan D, Ballard-Barbash R, Graubard B, Atienza AA: Joint associations of physical activity and sedentary behaviors with body mass index: results from a time use survey of us adults. Int J Obes 2009;33: 1427-1436.

-9 Travier N, Agudo A, May AM, Gonzalez C, Luan J, Besson H, Wareham NJ, Slimani N, Rinaldi S, Clavel-Chapelon F, Boutron-Ruault MC, Palli D, Agnoli C, Mattiello A, Tumino R, Vineis P, Rodriguez L, Sanchez MJ, Dorronsoro M, Barricarte A, Tormo MJ, Norat T, Mouw T, Key TJ, Spencer EA, Bueno-de-Mesquita HB, Vrieling A, Orfanos P, Naska A, Trichopoulou A, Rohrmann S, Kaaks R, M. Bergmann M, Boeing H, Hallmans G, Johansson I, Manjer J, Lindkvist B, Jakobsen MU, Overvad K, Tjonneland A, Halkjaer J, Lund E, Braaten T, Odysseos A, Riboli E, Peeters PH: Smoking and body fatness measurements: a cross-sectional analysis in the EPIC-PANACEA study. Prev Med 2009;49:365-373.

10 Ball K, Crawford D: Socioeconomic status and weight change in adults: a review. Soc Sci Med 2005;60:19872010.

11 Trichopoulou A, Gnardellis C, Lagiou A, Benetou V, Trichopoulos D: Body mass index in relation to energy intake and expenditure among adults in Greece. Epidemiology 2000;11:333-336.

12 Freedman MR, King J, Kennedy E: Popular diets: a scientific review. Obes Res 2001;9(suppl 1):1S-40S.

$\$ 13$ Davis JN, Hodges VA, Gillham MB: Normal-weight adults consume more fiber and fruit than their age- and height-matched overweight/obese counterparts. J Am Diet Assoc 2006;106:833-840.

14 Scali J, Siari S, Grosclaude P, Gerber M: Dietary and socio-economic factors associated with overweight and obesity in a southern French population. Public Health Nutr 2004;7:513-522.

15 Hasselbalch AL, Heitmann BL, Kyvik KO, Sorensen TI: Associations between dietary intake and body fat independent of genetic and familial environmental background. Int J Obes 2010;34:892-898.

16 Ballard-Barbash R, Graubard I, Krebs-Smith SM, Schatzkin A, Thompson FE: Contribution of dieting to the inverse association between energy intake and body mass index. Eur J Clin Nutr 1996;50:98-106.

$\checkmark 17$ Cade BS, Noon BR: A gentle introduction to quantile regression for ecologists. Front Ecol Environ 2003;1: 412-420.

18 Koenker R, Hallock K: Quantile regression. J Econ Perspect 2001;15:143-156.

-19 Heuer T, Krems C, Moon K, Brombach C, Hoffmann I: Food consumption of adults in Germany: results of the German National Nutrition Survey II based on diet history interviews. Br J Nutr 2015;113:1603-1604.

20 Lohman TG, Roche AF, Martorell R (eds): Anthropometric Standardization Reference Manual, Champaign, Human Kinetics Books, 1988.

21 Mensink GBM, Haftenberger M, Thamm M: Validity of dishes 98, a computerised dietary history interview: energy and macronutrient intake. Eur J Clin Nutr 2001;55:409-417.

-22 Hartmann BM, Heuer T, Hoffmann I: The German Nutrient Database: effect of different versions on the calculated energy and nutrient intake of the German population. J Food Compost Anal 2015;42:26-29.

23 Deutsche Gesellschaft für Ernährung (DGE): Lebensmittelbezogene Ernährungsempfehlungen in Deutschland (food-related recommendations in Germany), 1st ed. Bonn, DGE, 2014. 
Moon et al.: Predictors of BMI Vary along the BMI Range of German Adults - Results of the German National Nutrition Survey II

24 Wittig F, Hoffmann I: Ernährungsmuster von Bio-Käufern und Nicht-Bio-Käufern; in Hoffmann I, Spiller A (eds): Auswertung der Daten der Nationalen Verzehrsstudie II (NVS II): Eine integrierte verhaltens- und lebensbasierte Analyse des Bio-Konsums. Karlsruhe/Göttingen, Max Rubner-Institut/Georg-AugustUniversity Göttingen, 2010, pp 51-68. http://orgprints.org/16665/ (last accessed January 30, 2017).

25 Winkler J, Stolzenberg H: Der Sozialschichtindex im Bundes-Gesundheitssurvey. Gesundheitswesen 1999; 61(suppl 2):S178-183.

-26 Goldberg GR, Black AE, Jebb SA, Cole TJ, Murgatroyd PR, Coward WA, Prentice AM: Critical evaluation of energy intake data using fundamental principles of energy physiology: 1. Derivation of cut-off limits to identify underrecording. Eur J Clin Nutr 1991;45:569-581.

27 Black AE: Critical evaluation of energy intake using the Goldberg cut-off for energy intake: basal metabolic rate. A practical guide to its calculation, use and limitations. Int J Obes Relat Metab Disord 2000;24:11191130.

28 Poslusna K, Ruprich J, de Vries JH, Jakubikova M, van’t Veer P: Misreporting of energy and micronutrient intake estimated by food records and 24 hour recalls, control and adjustment methods in practice. Br J Nutr 2009; 101(suppl 2):S73-S85.

29 Spencer EA, Appleby PN, Davey GK, Key TJ: Validity of self-reported height and weight in 4808 EPIC-Oxford participants. Public Health Nutr 2002;5:561-565.

-30 Stommel M, Schoenborn CA: Accuracy and usefulness of BMI measures based on self-reported weight and height: Findings from the NHANES \& NHIS 2001-2006. BMC Public Health 2009; 9:421.

-31 Caman OK, Calling S, Midlov P, Sundquist J, Sundquist K, Johansson SE: Longitudinal age-and cohort trends in body mass index in Sweden - a 24-year follow-up study. BMC Public Health 2013;13:893.

-32 Nooyens AC, Visscher TL, Verschuren WM, Schuit AJ, Boshuizen HC, van Mechelen W, Seidell JC: Age, period and cohort effects on body weight and body mass index in adults: the Doetinchem Cohort Study. Public Health Nutr 2009;12:862-870.

33 Elia M: Obesity in the elderly. Obes Res 2001;9(suppl 4):244S-248S.

34 McLaren L: Socioeconomic status and obesity. Epidemiol Rev 2007;29:29-48.

-35 Ovaskainen ML, Paturi M, Tapanainen H, Harald K: Educational differences in the diet of Finnish adults and the associations between education and the determinants and facilitators of dietary fat quality. Public Health Nutr 2010;13:925-931.

-36 Perrin AE, Simon C, Hedelin G, Arveiler D, Schaffer P, Schlienger JL: Ten-year trends of dietary intake in a middle-aged French population: relationship with educational level. Eur J Clin Nutr 2002;56:393-401.

-37 Dibsdall LA, Lambert N, Bobbin RF, Frewer LJ: Low-income consumers' attitudes and behaviour towards access, availability and motivation to eat fruit and vegetables. Public Health Nutr 2003;6:159-168.

-38 Rosenthal L, Carroll-Scott A, Earnshaw VA, Santilli A, Ickovics JR: The importance of full-time work for urban adults' mental and physical health. Soc Sci Med 2012;75:1692-1696.

39 Roos E, Talala K, Laaksonen M, Helakorpi S, Rahkonen O, Uutela A, Prattala R: Trends of socioeconomic differences in daily vegetable consumption, 1979-2002. Eur J Clin Nutr 2008;62:823-833.

$\checkmark 40$ Molarius A, Berglund K, Eriksson C, Lambe M, Nordstrom E, Eriksson HG, Feldman I: Socioeconomic conditions, lifestyle factors, and self-rated health among men and women in Sweden. Eur J Public Health 2007;17: 125-133.

41 Mansson NO, Merlo J: The relation between self-rated health, socioeconomic status, body mass index and disability pension among middle-aged men. Eur J Epidemiol 2001;17:65-69.

-42 Stamatakis E, Hirani V, Rennie K: Moderate-to-vigorous physical activity and sedentary behaviours in relation to body mass index-defined and waist circumference-defined obesity. Br J Nutr 2009;101:765-773.

-43 Molarius A, Seidell JC, Kuulasmaa K, Dobson AJ, Sans S: Smoking and relative body weight: an international perspective from the WHO Monica Project. J Epidemiol Community Health 1997;51:252-260.

44 Jeffery RW, Rick AM: Cross-sectional and longitudinal associations between body mass index and marriagerelated factors. Obes Res 2002;10:809-815.

45 Lee S, Cho E, Grodstein F, Kawachi I, Hu FB, Colditz GA: Effects of marital transitions on changes in dietary and other health behaviours in US women. Int J Epidemiol 2005;34:69-78.

46 Gao SK, Beresford SA, Frank LL, Schreiner PJ, Burke GL, Fitzpatrick AL: Modifications to the healthy eating index and its ability to predict obesity: the multi-ethnic study of atherosclerosis. Am J Clin Nutr 2008;88: 64-69.

47 Kennedy ET, Bowman SA, Spence JT, Freedman M, King J: Popular diets: correlation to health, nutrition, and obesity. J Am Diet Assoc 2001;101:411-420.

48 Eisinger-Watzl M, Strassburg A, Ramunke J, Krems C, Heuer T, Hoffmann I: Comparison of two dietary assessment methods by food consumption: results of the German National Nutrition Survey II. Eur J Nutr 2015;54:343-354. 


\title{
Erratum
}

In the article by Moon K, Krems C, Heuer T, Roth A, Hoffmann I: Predictors of BMI Vary along the BMI Range of German Adults - Results of the German National Nutrition Survey II. Obes Facts 2017;10:38-49 the author affiliations are inaccurately given.

The correct author affiliations are as follows:

\author{
Kilson Moon ${ }^{\mathrm{a}}$ Carolin Krems $^{\mathrm{a}}$ Thorsten Heuer ${ }^{\mathrm{a}} \quad$ Alexander Roth $^{\mathrm{b}, c}$ Ingrid Hoffmann ${ }^{\mathrm{a}}$ \\ ${ }^{a}$ Department of Nutritional Behaviour, Max Rubner-Institut, Federal Research Institute of Nutrition \\ and Food, Karlsruhe, Germany; ${ }^{b}$ Department of Physiology and Biochemistry of Nutrition, \\ Max Rubner-Institut, Federal Research Institute of Nutrition and Food, Karlsruhe, Germany; \\ 'Department of Child and Adolescent Psychiatry and Psychotherapy, University of Zurich, Zurich, \\ Switzerland (present address)
}

